\title{
Adsorption and Photo-catalytic Properties of Congo Red by Cobalt Doped Porous ZnO Prepared Through Hydrothermal Method
}

\author{
Wenya Bao ${ }^{1, *}$, Xiaofen $\mathrm{Fu}^{1}$, Kaiqi $\mathrm{Hu}^{1}$, and Yecong Zhao ${ }^{1}$ \\ ${ }^{1}$ School of Chemical and Biological Engineering, Qilu Institute of Technology, Jinan, Shandong, 250200, China
}

\begin{abstract}
ZnO}$ and cobalt doped $\mathrm{ZnO}$ were prepared by hydrothermal method with zinc acetate dihydrate, cobalt acetate tetrahydrate and urea as raw materials and sodium citrate as surface modifier. Congo red (CR) was used as the pollutant model for adsorption and photo-catalytic experiments. Under the same conditions, the adsorption effect of cobalt doped $\mathrm{ZnO}$ with different urea content on $\mathrm{CR}$ was investigated, and the optimum urea content was determined. Under the same conditions, the adsorption and photocatalytic properties of cobalt doped $\mathrm{ZnO}$ prepared with the best urea content at different annealing temperatures were studied. According to the analysis of experimental data, the adsorption effect of Co doped $\mathrm{ZnO}$ with urea content of $8 \mathrm{mmol}$ and annealing temperature of $300^{\circ} \mathrm{C}$ is the best, and the photocatalytic effect is also the best under the same conditions.
\end{abstract}

\section{Introduction}

The shortage of fresh water resources is a common global problem. China uses the most water, the utilization rate of fresh water resources is low, and the distribution of water resources in the central and western regions is not balanced. With the gradual improvement of human living standards and the development of industry, untreated industrial wastewater, printing and dyeing industry discharge sewage also increase[1]. This wastewater contains a large number of harmful substances, which are difficult to degrade and toxic. Wastewater with much organics, high chromaticity and alkalinity, once into the water, will not only change the overall quality of water, the light into the water can also be blocked. It will eventually affect the water COD and BOD, and thus affecting the survival of animals, plants and microorganisms living in the water system. This will have a great impact on the development of human society and physical health.

$\mathrm{CR}$ is an important industrial dye and can be used for biological dyeing, adsorption indication and acid-base indication [2]. The dye has good thermal and chemical stability and is difficult to degrade under normal conditions. And it has a carcinogenic risk to human body, so industrial wastewater containing $\mathrm{CR}$ needs to be treated before discharged [3].

The wastewater treatment generally includes chemical oxidation [4, 5], biodegradation [6], membrane technology [7], adsorption [8] and photo-catalysis [9]. The adsorption and photo-catalytic method has attracted much attention due to its simple operation, low cost and wide application range. Therefore, it is an urgent problem to find adsorbents with low price, large adsorption capacity and good selectivity for wastewater treatment technology. Many nanomaterials have good adsorption and photo-catalytic properties for organic dyes. Metal oxide nanomaterials possess high stability and simple preparation and will be potential photocatalyst. Porous $\mathrm{ZnO}$ can be used as adsorbent due to its controllable morphology, small size and large specific surface area[10].

$\mathrm{ZnO}$ is a semiconductor material with a large energy gap $(3.4 \mathrm{eV})$ and excellent optical properties. Under ultraviolet light, valence band electrons can transition to conduction band, and it has good photocatalytic performance [11]. Porous $\mathrm{ZnO}$ has many active sites, multiple pores, large specific surface area and other advantages, which are the key factors to be applied in wastewater treatment [12]. Therefore, it is of great significance to explore the interrelation between adsorption and photocatalytic performance of porous $\mathrm{ZnO}$.

The synthesis method of porous $\mathrm{ZnO}$ has been gradually mature after years of development. There are many preparation methods of porous $\mathrm{ZnO}$, such as solid phase, gas phase and liquid phase, among which liquid phase is the most commonly used synthesis method. Liquid phase method generally includes sol-gel method [13], direct precipitation method [14], microemulsion method [15] and hydrothermal synthesis method [16]. Compared with other preparation methods, the hydrothermal synthesis method is simple and the prepared $\mathrm{ZnO}$ has the good crystallinity, easy grain dispersion, small particle size and uniform distribution.

In this paper, we use hydrothermal synthesis method to prepare $\mathrm{ZnO}$ and cobalt doped $\mathrm{ZnO}$ materials to study the adsorption performance and photocatalytic

\footnotetext{
*Corresponding author: sdbaowenya@163.com
} 
performance of CR. The optimal urea content was determined by studying the influence of $\mathrm{ZnO}$ with different urea content on the adsorption performance of $\mathrm{CR}$. Based on this, the influence of cobalt doped $\mathrm{ZnO}$ on the adsorption and photocatalytic performance of $\mathrm{CR}$ under different annealing temperature was discussed.

\section{Experimental section}

\subsection{Chemicals for synthesis}

Zinc acetate dehydrate $\left[\mathrm{Zn}\left(\mathrm{CH}_{3} \mathrm{COO}\right)_{2} \cdot 2 \mathrm{H}_{2} \mathrm{O}\right]$, urea [CO $\left.\left(\mathrm{NH}_{2}\right)\right]$ and Trisodium citrate $\left[\mathrm{Na}_{3} \mathrm{C}_{6} \mathrm{H}_{5} \mathrm{O}_{7} \cdot 5 \mathrm{H}_{2} \mathrm{O}\right]$ were purchased from Tianjin Damao Chemical Reagent Factory. Cobalt acetate tetrahydrate $\left[\mathrm{Co}\left(\mathrm{CH}_{3} \mathrm{COO}\right)_{2} \cdot 4 \mathrm{H}_{2} \mathrm{O}\right]$ and $\mathrm{CR}$ was purchased from Tianjin Kemio Chemical Reagent co., LTD and Shanghai Chemical Industrial Company respectively. All chemicals used were analytical grade and without further purifying.

\subsection{Synthesis of samples}

Porous cobalt doped $\mathrm{ZnO}$ simples were synthesized using a simple hydrothermal synthesis method as previously described. Typically, $2 \mathrm{mmol}$ $\mathrm{Zn}\left(\mathrm{CH}_{3} \mathrm{COO}\right)_{2} \cdot 2 \mathrm{H}_{2} \mathrm{O}, 0.028 \mathrm{mmol} \mathrm{Co}\left(\mathrm{CH}_{3} \mathrm{COO}\right)_{2} \cdot 4 \mathrm{H}_{2} \mathrm{O}$ $6 \mathrm{mmol} \mathrm{CO}\left(\mathrm{NH}_{2}\right)$ and $1 \mathrm{mmol} \mathrm{Na}_{3} \mathrm{C}_{6} \mathrm{H}_{5} \mathrm{O}_{7} \cdot 5 \mathrm{H}_{2} \mathrm{O}$ were dissolved and stirred in $60 \mathrm{~mL}$ deionized water. After continuous magnetic stirring for $30 \mathrm{~min}$, the liquid above was transferred into Teflon reactor. Then put the Teflon reactor into the $120{ }^{\circ} \mathrm{C}$ oven for $12 \mathrm{~h}$. After natural cooling, the precursor was collected through washing with deionized water for three times, dried at $80^{\circ} \mathrm{C}$ for $6 \mathrm{~h}$ and annealed at different temperature $\left(200{ }^{\circ} \mathrm{C}, 300^{\circ} \mathrm{C}\right.$, $400^{\circ} \mathrm{C}$ and $500^{\circ} \mathrm{C}$ ) for $2 \mathrm{~h}$ in air. A black-green product (cobalt doped $\mathrm{ZnO}$ ) was obtained, and the pure $\mathrm{ZnO}$ was prepared under similar reaction conditions except for the addition of $\mathrm{Co}\left(\mathrm{CH}_{3} \mathrm{COO}\right)_{2} \cdot 4 \mathrm{H}_{2} \mathrm{O}$.

\subsection{Evaluation of adsorption performance}

To investigate the effect of cobalt doped $\mathrm{ZnO}$ on adsorption performance, cobalt doped $\mathrm{ZnO}$ and pure $\mathrm{ZnO}$ samples were mixed with $\mathrm{CR}$ aqueous solution respectively in beakers under stirring in the dark. To study adsorption kinetic, $25 \mathrm{mg}$ of the $\mathrm{ZnO}$ and the cobalt doped $\mathrm{ZnO}$ samples are mixed with $30 \mathrm{~mL} \mathrm{CR}$ solution $(300 \mathrm{mg} / \mathrm{L})$ respectively at different times. After centrifugation, the concentrations after adsorption of CR solutions were measured on UV-1750 ultraviolet-visible spectrometer (Shimadzu). The removal percentage $(\eta)$ of as-prepared samples is calculated by Eq. (1).

$$
\eta=\frac{A_{0}-A_{\mathrm{t}}}{A_{0}} \times 100 \%
$$

In the above formula, $A_{0}$ and $A_{\mathrm{t}}$ are the absorbance of CR solution initially and at time $t$.

\subsection{Evaluation of photo-catalytic performance}

The CR solution with a concentration of $300 \mathrm{mg} / \mathrm{L}$ was measured in $30 \mathrm{~mL}$ in $50 \mathrm{~mL}$ beakers, and $25 \mathrm{mg}$ of cobalt doped $\mathrm{ZnO}$ at different annealing temperatures was added. After stirring for $60 \mathrm{~min}$ away from light for adsorption saturation, then put the suspension liquid under $200 \mathrm{~W}$ Xenon lamp for $60 \mathrm{~min}$ under stirring. Then centrifuge for $15 \mathrm{~min}$ at the speed of $10000 \mathrm{r} / \mathrm{min}$, the concentrations of $\mathrm{CR}$ solutions were measured on ultraviolet-visible spectrometer. The photocatalytic degradation rate was calculated by Eq. (1).

\section{Results and discussion}

\subsection{Effect of urea content on adsorption performance}

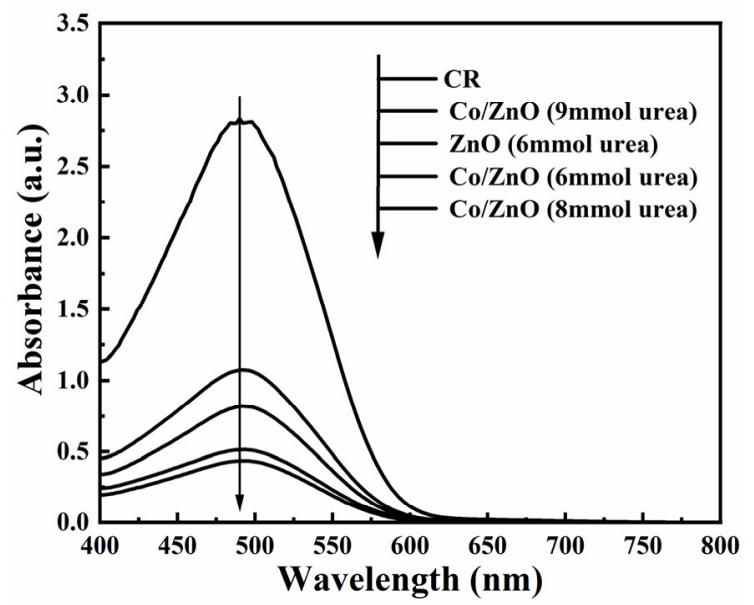

Fig. 1. Spectrogram of absorption of $\mathrm{CR}$ by cobalt doped $\mathrm{ZnO}$ with different urea content.

As can be seen from Figure 1, when the urea content is $8 \mathrm{mmol}$, the absorbance of the prepared cobalt doped $\mathrm{ZnO}$ to $\mathrm{CR}$ is the lowest at $497 \mathrm{~nm}$, which is 0.4353 , indicating that the adsorption performance of $\mathrm{CR}$ is the best when the urea content is $8 \mathrm{mmol}$. In addition, cobalt doped $\mathrm{ZnO}$ has a better adsorption effect on $\mathrm{CR}$ than pure $\mathrm{ZnO}$. It may be that $\mathrm{Co}^{2+}$ occupies the position of $\mathrm{Zn}^{2+}$ in the $\mathrm{ZnO}$ lattice, resulting in a decrease in the pore diameter of $\mathrm{ZnO}$, and increasing the specific surface area, thus improving the adsorption effect. The adsorption rates of each group are calculated by Formula (1), and the removal percentages are shown in Table 1.

Table 1. Removal percentage of cobalt doped $\mathrm{ZnO}$ with different urea content.

\begin{tabular}{|c|c|}
\hline Urea content/mmol & Removal percentage/\% \\
\hline 6 & 81.93 \\
\hline 8 & 84.63 \\
\hline 9 & 62.05 \\
\hline
\end{tabular}




\subsection{Effect of annealing temperature on adsorption performance}

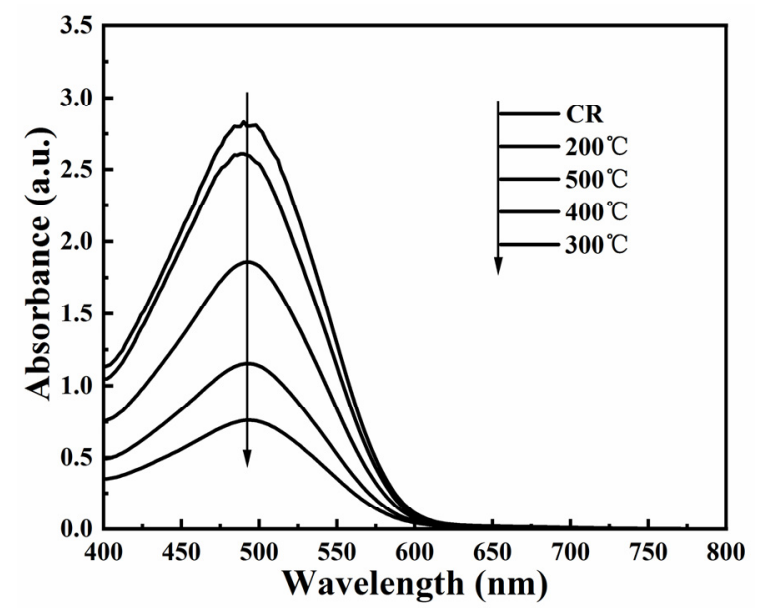

Fig. 2. Spectrogram of absorption of $\mathrm{CR}$ by cobalt doped $\mathrm{ZnO}$ with different annealing temperature.

As Figure 2 shows, when the annealing temperature is at $300^{\circ} \mathrm{C}$, the absorbance of $\mathrm{CR}$ solution by cobalt doped $\mathrm{ZnO}$ is the lowest, indicating that the sample has the best adsorption ability to $\mathrm{CR}$ solution under this condition. When the annealing temperature is higher than $300^{\circ} \mathrm{C}$, the absorbance increases gradually and the removal percentage decreases with the increase of annealing temperature. It may be because when the annealing temperature increases, the particle size and pore size of $\mathrm{ZnO}$ generally increase. While the specific surface area and pore volume decrease, and the pore structure begins to collapse, resulting in the decrease of surface active sites, thus affecting the adsorption effect of CR. When the annealing temperature is at $200^{\circ} \mathrm{C}$, the absorbance of CR solution by cobalt doped $\mathrm{ZnO}$ is the highest, second only to the original solution $(300 \mathrm{mg} / \mathrm{L})$. This indicates that cobalt doped $\mathrm{ZnO}$ has the worst adsorption ability on CR solution under this condition, which may be due to the low annealing temperature and poor crystallinity, and the precursor does not form $\mathrm{ZnO}$. The removal percentage of each group are respectively calculated by Formula (1). See Table 2 for each removal percentage.

Table 2. Removal percentage of cobalt doped $\mathrm{ZnO}$ with different annealing temperature.

\begin{tabular}{|c|c|}
\hline $\begin{array}{c}\text { Annealing } \\
\text { temperature } /{ }^{\circ} \mathrm{C}\end{array}$ & Removal percentage $/ \%$ \\
\hline 200 & 7.28 \\
\hline 300 & 72.97 \\
\hline 400 & 58.97 \\
\hline 500 & 34.03 \\
\hline
\end{tabular}

\subsection{Effect of annealing temperature on photo- catalytic performance}

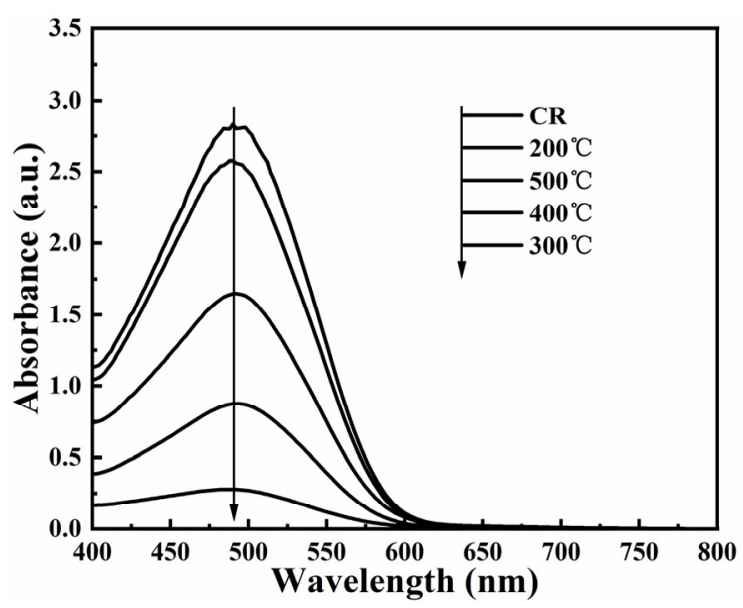

Fig. 3. Spectrogram of photocatalytic performance of CR by cobalt doped $\mathrm{ZnO}$ with different annealing temperature.

From Figure 3, we can see that cobalt doped $\mathrm{ZnO}$ has little catalytic degradation effect on $\mathrm{CR}$ solution at the annealing temperature of $200{ }^{\circ} \mathrm{C}$. When the annealing temperature is at $300^{\circ} \mathrm{C}$, the adsorption of $\mathrm{CR}$ solution by cobalt doped $\mathrm{ZnO}$ is the lowest, indicating that the photo-catalytic degradation effect is the best. The photocatalytic percentages of each group are calculated by Formula (1), and shown in Table 3. While the annealing temperature is higher than $300{ }^{\circ} \mathrm{C}$, the photo-catalytic degradation rate decreases with the increasing of annealing temperature. The same as the adsorption effect, the photo-catalytic ability is still the best when the annealing temperature is $300{ }^{\circ} \mathrm{C}$, indicating that the photo-catalytic effect is directly related to the adsorption effect. This may be because when the annealing temperature is $300^{\circ} \mathrm{C}$, there are more active sites formed on the surface of cobalt doped $\mathrm{ZnO}$, which can make good use of light source for photo-generating electrons to further improve the photo-catalytic degradation rate. When the temperature is lower than $300^{\circ} \mathrm{C}$, the poor photo-catalytic degradation effect may be caused by the low temperature of the precursor annealing, resulting in poor crystallinity, structural instability, less photogenerated electrons, and slow electron transfer, etc. When the temperature is higher than $300^{\circ} \mathrm{C}$, the crystal sintering may cause uneven crystal lattice and affect the photo-generated electrons of the sample, thus affecting the degradation effect of CR.

Table 3. Photo-catalytic degradation rate of cobalt doped $\mathrm{ZnO}$ with different annealing temperature.

\begin{tabular}{|c|c|}
\hline $\begin{array}{c}\text { Annealing } \\
\text { temperature } /{ }^{\circ} \mathrm{C}\end{array}$ & $\begin{array}{c}\text { Photo-catalytic degradation } \\
\text { rate } / \%\end{array}$ \\
\hline 200 & 8.49 \\
\hline 300 & 90.12 \\
\hline 400 & 68.92 \\
\hline
\end{tabular}




\begin{tabular}{|l|l|}
\hline 500 & 41.46 \\
\hline
\end{tabular}

\section{Conclusion}

In this study, $\mathrm{ZnO}$ and cobalt doped $\mathrm{ZnO}$ prepared by hydrothermal synthesis method with different urea content and annealing temperature. The results show that the adsorption and photo-catalytic performance on $\mathrm{CR}$ solution were the best with the urea content of $8 \mathrm{mmol}$ and the annealing temperature at $300^{\circ} \mathrm{C}$.

\section{Acknowledgments}

The research was supported by the student innovation program of Qilu Institute Technology (DC2019072).

\section{References}

1. S. Hokkanen, A. Bhatnagar, M. Sillanpää. A review on modification methods to cellulose-based adsorbents to improve adsorption capacity[J]. Water research, 2016, 91: 156-173.

2. Y. Zheng, B. Zhu, H. Chen, W. You, C. Jiang, J. Yu, Hierarchical flower-like nickel(II) oxide microspheres with high adsorption capacity of Congo red in water, J. Colloid Interface Sci. (2017,504, 688-696.

3. M.H. Beyki, M. Bayat, F. Shemirani. Fabrication of core-shell structured magnetic nanocellulose base polymeric ionic liquid for effective biosorption of Congo red dye[J]. Bioresource technology, 2016, 218: 326-334.

4. A.J. Santos, I. Sirés, A.P.M. Alves, et al. Vermiculite as heterogeneous catalyst in electrochemical Fentonbased processes: Application to the oxidation of Ponceau SS dye[J]. Chemosphere, 2020, 240: 124838 .

5. C.W. Zhu, C.Q. Jiang, S. Chen, et al. Ultrasound enhanced electrochemical oxidation of alizarin red on boron doped diamond (BDD) anode: effect of degradation process parameter[J]. Chemosphere, 2018, 209: 685-695.

6. W. Sun, C. Zhang, J. Chen, et al. Accelerating biodegradation of a monoazo dye Acid Orange 7 by using its endogenous electron donors[J]. Journal of hazardous materials, 2017, 324: 739-743.

7. W. Chen, J. Mo, X. Du, et al. Biomimetic dynamic membrane for aquatic dye removal[J]. Water research, 2019, 151: 243-251.

8. H. Jin, J. Yuan, H. Hao, et al . The exploration of a new adsorbent as $\mathrm{MnO}_{2}$ modified expanded graphite[J]. Materials Letters, 2013, 110.

9. Q. Li, T. Zhao, M. Li, et al. One-step construction of Pickering emulsion via commercial $\mathrm{TiO}_{2}$ nanoparticles for photocatalytic dye degradation[J]. Applied Catalysis B: Environmental, 2019, 249: 1-8.
10. A. Serrà, Y. Zhang, B. Sepúlveda, et al. Highly reduced ecotoxicity of ZnO-based micro/nanostructures on aquatic biota: Influence of architecture, chemical composition, fixation, and photocatalytic efficiency[J]. Water research, 2020, 169: 115210.

11. J. Wang, S. Fan, Y. Xia, et al. Room-temperature gas sensors based on $\mathrm{ZnO}$ nanorod/Au hybrids: Visiblelight-modulated dual selectivity to $\mathrm{NO}_{2}$ and $\mathrm{NH}_{3}[\mathrm{~J}]$. Journal of hazardous materials, 2020, 381: 120919.

12. X.L. Li, J. Zhang, Y.C. Jiang, et al. Highly efficient biode-colorization / degradation of congo red and alizarinyellow by chloroperoxidase from caldariomyces fuma-go: catalytic mechanism and degradation pathway[J]. Industrial \& Engineering Chemistry Research, 2013, 52: 13572-13579.

13. P.C. Bhomick, A. Supong, M. Baruah, et al. Pine Cone biomass as an efficient precursor for the synthesis of activated bio-carbon for adsorption of anionic dye from aqueous solution: isotherm, kinetic, thermodynamic and re-generation studies[J]. Sustainable Chemistry and Pharmacy, 2018, 10: 4149.

14. C. Lei, M. Pi, C. Jiang, et al. Synthesis of hierarchical porous zinc oxide $(\mathrm{ZnO})$ microspheres with highly efficient adsorption of Congo $\operatorname{red}[\mathrm{J}]$. Journal of colloid and interface science, 2017, 490: 242-251.

15. X. Han, J. Harris, L. Šiller. Synthesis of porous zincbased/zinc oxide composites visol-gel and ambient pressure drying routes. Journal of Materials Science. 2018, 018, 2138.

16. D. Pinheiro, S. Devi, A. Jose, R. Bharadwa. Effect of surface charge and other critical parameters on the adsorption of dyes on SLS coated $\mathrm{ZnO}$ nanoparticles and optimization using response surface methodology[J]. Journal of Environmental Chemical Engineering, 2020, 8(4).

17. A. Ishizumi, Y. Kanemitsu. Structural and luminescence properties of Eu-doped $\mathrm{ZnO}$ nanorods fabricated by a microemulsion method[J]. Applied Physics Letters, 2005, 86(25).

18. O. Akhavan, M. Mehrabian, K. Mirabbaszadeh, et al. Hydrothermal synthesis of $\mathrm{ZnO}$ nanorod arrays for photocatalytic inactivation of bacteria[J]. Journal of Physics D: Applied Physics, 2009, 42(22): 225305. 